\title{
OS PRINCIPAIS FITOTERAPICOS QUE AUXILIAM NO CONTROLE DA DIABETES TIPO II
}

\author{
Rosani Guedes \\ Enfermeira (PUC Campinas), Pós-Graduada em Enfermagem do \\ Trabalho (UNIP-Campinas), Pós-Graduada em Arteterapia - UNICAMP \\ rosaniguedes@gmail.com
}

INTRODUÇÃO: As plantas medicinais possuem princípios ativos que podem tratar, curar ou prevenir doenças em seres humanos. Apesar da grande influência da mídia e do crescente número de farmácias que comercializam plantas medicinais e fitoterápicos em todo o país, ainda é frequente o senso comum da população de que estes medicamentos, são inócuos ou desprovidos de efeitos colaterais e/ou adversos. Há um grande número de espécies vegetais utilizadas com efeito hipoglicemiante. OBJETIVO: Este trabalho teve como objetivo coletar os principais fitoterápicos com efeito hipoglicemiante utilizados no tratamento da Diabetes tipo II, comparando a melhora nos exames bioquímicos/laboratoriais e sinais clínicos. MÉTODO: Trata-se de um trabalho de revisão sistêmica da literatura cientifica. Realizou-se pesquisa exploratória bibliográfica nas seguintes bases de dados eletrônicas: Pubmed, Scielo e Lilacs. RESULTADOS: Foram encontrados 19 artigos, entre os anos de 2010 a 2017, após aplicados os critérios de inclusão e exclusão resultaram em 13. Nos artigos encontrados foram citadas algumas plantas medicinais que possuem ação hipoglicemiante, e as mais citadas foram: Pata de Vaca (Bauhinia forficata), Carqueja (Baccharis trimera), Jamelão (Syzygium cumini), Alho (Allium sativum), Melão Amargo (Momordica charantia) e Cajueiro/Caju (Anacardium occidentale). CONCLUSÃO: Entretanto, é necessária um maior conhecimento e conscientização da população e dos profissionais da área de saúde sobre o uso e efeitos destas plantas medicinais no tratamento de Diabetes Mellitus tipo II.

Palavras-chave: Fitoterápicos. Diabetes tipo II. Sinais e sintomas. 